\title{
Teaching vocabulary to young second- or foreign-language learners
}

\section{What can we learn from the research?}

\author{
Yuko Goto Butler \\ University of Pennsylvania
}

\begin{abstract}
While vocabulary knowledge is considered a foundational element for young learners of a second or foreign language (L2/FL), pedagogically useful information on this topic is not easily accessible for practitioners. This is in part due to the fact that the relevant information is scattered across multiple fields, including first-language acquisition, child development, and education. The aim of this paper is to synthesize recent knowledge from the related fields and to provide theoretically sound and evidence-based information that is useful for teaching vocabulary to young learners of L2/FL. I identify four major recommendations for vocabulary instruction: (a) ensure frequent and repeated exposure to the target words (as well as nontarget words); (b) provide explicit word definitions and meanings in context; (c) create opportunities for discussions and interactions around the words in question; and (d) use multimodal approaches to teach vocabulary. I also suggest future research directions, with the goal of finding effective approaches that teachers can use to improve their vocabulary instruction while meeting the specific needs of their young L2/FL students.
\end{abstract}

Keywords: young learners, vocabulary learning, vocabulary teaching, implicit learning, explicit learning, input-based tasks, interactions, formulaic language

\section{Introduction}

A growing number of children are learning a second or foreign language (L2/ FL) in instructional settings. Vocabulary is considered a foundational element for language development. According to Marulis and Neuman (2010), for example, "vocabulary is at the heart of oral language comprehension and sets the foundation for domain-specific knowledge and later reading comprehension" (p.300). 
Some reports have even indicated that the effect of vocabulary knowledge on reading comprehension is greater for young L2/FL learners than for monolingual first language (L1) learners (Lervåg \& Aukrust, 2010). Indeed, how best to support children's L2/FL vocabulary learning has been of great interest to many educators. Despite the demand for pedagogically useful information in this area, teachers have access to relatively few instructional resources. Much of the vocabulary research that has been done in second language acquisition (SLA) has largely been developed around adult L2 learners. And the entire body of relevant research is scattered across multiple fields, including L1 acquisition, child development, education, and SLA, making it difficult for L2/FL educators to gain a state-of-the-art understanding of young L2/FL learners' vocabulary learning and instruction. Although by no means exhaustive, this review aims to synthesize knowledge from different fields and to provide theoretically sound and evidencebased information to support the teaching of vocabulary to young L2/FL learners (defined as children up to age 12). I primarily depend on studies published after 2000 in international journals, which I identified through major electronic data bases including PsychINFO, ISI Web Science, ERIC, Education Abstract, Google Scholar, and so forth.

The paper consists of three sections. As a way of offering a background, I begin with a summary of basic mechanisms of vocabulary learning among young learners. I also identify possible differences and similarities between young L2/FL and L1 learners as well as between children and adult L2/FL learners. The second section identifies and describes major instructional methods that have been found to be effective in assisting children learn L2/FL vocabulary. In the final section, I identify what is missing in our current understanding of vocabulary teaching to young learners and suggest areas for further research and instruction.

\section{General mechanisms of learning vocabulary}

\subsection{Heterogeneity of the target group}

Children's vocabulary acquisition can vary according to an array of variables, including the number of languages that a child is exposed to (i.e., monolinguals, bilinguals, and multilinguals), the age of exposure to the target language(s), the amount of exposure, the nature of the input (i.e., natural or instructional contexts), the types of instruction received, the socioeconomic conditions of learning, and individual factors such as the motivation level and memory capacity of the learner (e.g., Fennell \& Lew-Williams, 2018; Granena \& Long, 2012; Marchman, Martínez, Hurtado, Grüter, \& Fernald, 2017; Marulis \& Neuman, 2010; Takanashi 
\& Menestrel, 2017). Vocabulary development studies focusing on L2/FL learners ages 4 to 12, the particular interest group in this paper, are relatively limited compared with vocabulary studies on child L1 acquisition (typically dealing with monolingual children up to preschool), bilingual L1 acquisition (targeting simultaneous bilinguals, usually up to preschool) as well as adult L2 studies. However, it is important to keep in mind that any of these traditionally defined target groups (e.g., L1-learning children, bilingual-L1 children, young L2/FL children, etc.) are by no means homogenous and, indeed, often overlap. Given the heterogeneity of the target population (namely, young L2/FL children), I do not make a distinction between L2-learning children and FL-learning children (L2-learning children presumably can have more extensive exposure to the target language than FLlearning children). Additionally, since some young L2/FL learners are exposed to the target language from birth, this review covers both simultaneous and sequential bilingual language learners. ${ }^{1}$ Finally, for the purposes of this review, I do not distinguish bilinguals from multilinguals; bilingual children in this chapter refer to children who speak two or more languages.

In understanding young L2/FL learners' vocabulary learning mechanisms and development, it is important to pay attention to the following two elements: (a) the role of having additional language(s) as opposed to acquiring one language; and (b) the role of age in vocabulary learning. I next discuss each of these elements in turn.

\subsection{The role of knowing an additional language}

Previously, researchers believed that children's vocabulary learning was essentially an act of mapping words with meaning and that learning vocabulary was a relatively easy task for children compared with acquiring other elements in language, such as grammar. More recently, however, researchers have begun to emphasize the complexity of vocabulary learning among children and to identify various challenges that they face (Westermann \& Mani, 2018). Infants first identify which

1. Conventionally, simultaneous bilinguals refers to individuals who have been exposed to more than one language simultaneously from birth. In contrast, the term sequential bilinguals is defined as language learners who start learning their additional language(s) after they developed their L1, although a precise cut-off onset age for L2 is unspecified. In the United States, the term dual language learners is sometimes used to refer to children age o to 5 who are developing language(s) other than their first (or home) language(s), and they are often distinguished from children who are first exposed to their L2 in a school setting (Takanishi \& Menestrel, 2017). In European contexts, the term additional language learners is more commonly used than L2 learners for referring to school-age children who are learning a language in addition to their L1 or home language(s). 
sounds are used in their language (i.e., phonemes). They next extract sequences of phonemes to form meaningful lexicon-like units out of streams of natural speech sounds, and then they associate them with meaning in context while dealing with environmental ambiguity and variability of input (e.g., different speakers use the same lexicon-like units with various accents in various environments). Children continuously refine their mental representation in this process (Westermann \& Mani, 2018).

Basic mechanisms of vocabulary learning appear to be very similar between monolingual and bilingual infants. For example, bilingual infants can learn two different phonotactic regularities - combinations of phonemes permitted in a given language system - as equally well as monolingual infants who deal with only one system (Fennell \& Lew-Williams, 2018). Likewise, bilingual infants show equivalent abilities to their monolingual counterparts when it comes to recognizing words from nonwords in languages that they are exposed to (Sebastian-Galles, 2010). Both monolingual and bilinguals infants have similar onsets for receptive and productive vocabularies (De Houwer, 2009). Finally, high correlations are found between the breadth and depth of vocabulary knowledge (how many words a child knows and how much a child knows about words) for both monolinguals and bilinguals (Vermeer, 2001).

Even though the basic mechanisms for vocabulary learning are similar for monolingual and bilingual infants, differences in the environmental elements to which infants are exposed appear to play a role in their vocabulary learning. Byers-Heinlein and Fennell (2013) listed four major environmental elements unique to bilinguals that potentially influence their language development: "(1) bilingual infants have less exposure to each language than monolinguals; (2) bilingual infants must simultaneously represent two different languages; (3) bilingual exposure is 'noisy'; and (4) bilingual infants must separate and differentiate their languages" (pp. 275-276). Importantly, the effect of being bilingual on a young child's vocabulary development - both in terms of vocabulary knowledge and lexical processing - largely depends on the amount and types of input that bilinguals have in each of their languages (Fennell \& Lew-Williams, 2018).

Being exposed to more than one language may delay some initial developmental processes, although such "delay" is usually a short term. For example, Fennel, Byers-Heinlein, and Werker (2007) reported that monolingual infants recognize minimal pairs (i.e., two words differing only in one phoneme) successfully by sometime around 17 months of age, while bilingual infants take a longer time (until 20 months of age) to be able to react to mislabeled objects that differ only by a phoneme. Interestingly, however, the researchers also found that 17-monthold monolingual infants could not learn a new word when it was pronounced by a bilingual speaker (i.e., when the pronunciation deviated from a monolingual 
speaker), while their bilingual counterparts could learn a word with the deviated pronunciation produced by a bilingual speaker. This result indicates bilinguals' greater adaptability to a variety of pronunciations, likely because of their exposure to phonetically diverse environments (Fennell \& Byers-Heinlein, 2014; Fennel \& Lew-Williams, 2018; also see Mattock, Polka, Rvachew, \& Krehm, 2010). When a learner's L1 and L2 are related lexically, there is also some evidence that bilingual children as young as kindergarteners, if not earlier, can recognize cognates, although their sensitivity to cognates depends on the amount of exposure to L1 and L2 (e.g., Pérez, Peña, \& Bedore, 2010, for a case of Spanish-English bilinguals). Furthermore, some studies report that vocabulary knowledge in L1 supports vocabulary growth in L2 longitudinally under certain contexts even between two unrelated languages (e.g., Pham, 2016, for a case of Vietnamese-Englishspeaking school-age sequential bilingual children), although precise mechanisms for such positive effects are not yet well understood.

Exposure to more than one language makes bilinguals less dependent on mutual exclusivity constraints when associating a novel word with an object. It has been suggested that such mutual exclusivity constraints, or the tendency to associate a novel word to a new object rather than objects for which they already have labels, can be attributed to monolingual children (Markman \& Wachtel, 1988). Mutual exclusivity can be a useful strategy for monolingual children, whose environment usually allows one-to-one mapping between a word and an object. But it seems to be a less attractive strategy for bilinguals, whose linguistic environments allow them to have more than one label for an object (e.g., Bosch \& Ramon-Casas, 2014; Byers-Heinlein \& Werker, 2013; Davison \& Tell, 2005; Houston-Price, Zoe, \& Raviglione, 2010). In Diesendruck (2005):3-4-year-old bilingual children were more likely to accept a second label for an object when interacting with a bilingual puppet than with a monolingual puppet, suggesting the children's pragmatic sensitivity to lexical-learning strategies.

One can assume that the above-mentioned bilingual environmental elements potentially influence not only the initial stages of vocabulary learning but also later lexical development among young L2/FL learners. It is frequently documented that bilingual preschool- and school-age children have smaller vocabulary sizes in each language (both receptive and productive vocabularies) than their monolingual peers (e.g., Carlo et al., 2004; Mancilla-Martinez \& Lesaux, 2011; Uccelli \& Páez, 2007) even after controlling for their socioeconomic status (SES) (Hoff et al., 2012) or irrespective of the students' L1-L2 combinations (Bialystok, Luk, Peets, \& Yang, 2010). However, evaluating bilinguals' vocabularies based on standardized measurements in just one language can be highly misleading. One can assume that bilingual children are likely to use $\mathrm{L}_{1}$ and $\mathrm{L}_{2}$ in different contexts for different purposes. Indeed, we have ample evidence showing that bilingual children's 
vocabularies in L1 and L2 do not greatly overlap. Peña, Bedore, and Zlatic-Giunta (2002), for example, reported that approximately $70 \%$ of vocabulary knowledge (in a category-generation task) of Spanish-English bilinguals (age 4-7) was unique to either their L1 or L2; only $30 \%$ of the words were produced in both languages. When researchers combined bilingual students' vocabulary scores in L1 and L2, or used a conceptual scoring method (i.e., giving credit for each concept that a bilingual student knows in either language), bilingual students' vocabulary scores were compatible with those of their monolingual counterparts (e.g., De Houwer, 2009; Goodrich \& Lonigan, 2018; Hoff et al., 2012; Pearson, Fernández, \& Oller, 1993).

Observed variability in bilinguals' vocabulary growth rate is also due to various individual variables rather than being bilingual per se. After controlling for major influential variables such as students' SES, nonverbal cognitive abilities, gender, daycare attendance, and so forth, MacLeod and colleagues (2018) in Québec, Canada, reported that bilingual children's vocabulary growth rates between 3.5 and 8 years of age were compatible with those of their monolingual peers. Interestingly, after controlling for such variables, there was no difference in growth rate between simultaneous and early sequential bilinguals. Moreover, for multilingual children who speak a minority language (i.e., children who speak a language other than English or French at home), although their vocabulary sizes in either English or French at school entry were smaller than their counterparts who are monolingual or majority-language-speaking bilingual, their vocabulary growth rate after entering school (i.e., after age 6) was compatible with that of the monolingual and majority-language-speaking bilinguals.

\subsection{The role of age}

Age is another critical factor in children's vocabulary learning. There are a number of age-related abilities and types of knowledge associated with vocabulary learning, including aural processing and capacities, cognitive capacities (e.g., working memory, inference skills), knowledge and processing of L1, general world knowledge and world experience, and learning environments. All these factors influence young learners' vocabulary development and might also distinguish it in important ways from adults' vocabulary learning.

There is a prevailing assumption among the general public that "the earlier, the better" for language learning. The validity of the so-called "critical period" in L2/FL acquisition has been a heated topic of debate among researchers (e.g., Butler, 2016; Muñoz \& Singleton, 2011). While there has been substantial research examining the relationship between the onset of L2/FL learning and ultimate attainments in phonology and morphosyntax, little is understood when it comes to vocabulary acquisition in relation to the onset of learning. Abrahamsson and 
Hyltenstam (2009) recruited Spanish-Swedish bilinguals who had self-identified as native-like Swedish L2 speakers and administered various measurements, including ones for idioms and proverbs, to the participants. They found that even the most advanced learners of L2 with early age of arrival (before age 11) attained substantially lower performance in both idioms and proverbs compared with native Swedish speakers; only $58 \%$ and $17 \%$, respectively, fell into the performance range of native speakers. Granena and Long (2012) examined L2 attainment among Spanish-learning Chinese speakers residing in Spain, and proposed multiple periods for attaining native-like proficiency depending on linguistic domains: before age 5 for phonology, age 9 for lexis-collocation, and age 12 for morphosyntax. Considering that the participants' aptitude scores, and memory components of aptitude in particular, were strongly correlated with their lexical/ collocation performance, Granena and Long postulated that lexical/collocation learning - a typical form of item-based learning - would be influenced greatly by implicit learning, which is a process of acquiring linguistic knowledge that is usually independent from intention and awareness. They suggested that the relatively early closure for vocabulary learning must be due to the availability of implicit learning, which presumably declines with age. However, whether one's vocabulary learning can entirely be done implicitly is a contested issue (Ellis, 2009). It might be the case that meaning always involves some degree of explicitness, even for children (N. Ellis, 1994).

As seen in Granena and Long (2012), there is a widely held assumption that one's implicit language learning declines with age. But empirical evidence concerning young L2/FL learners' changes in implicit and explicit learning over time is limited. Little is understood about the precise roles that implicit and explicit learning play in vocabulary development in relation to the learner's age, and this is, in part, due to varied and ambiguous conceptualizations about the nature of implicit and explicit learning (i.e., the process of learning) as well as the knowledge resulting from such processes. While implicit and explicit learning and knowledge are often associated with consciousness and unconsciousness, respectively, Schmidt (1994) argued that researchers discuss consciousness in four different senses: (a) consciousness as intentionality (intentional vs. incidental learning); (b) consciousness as attention (focal attention or noticing vs. peripheral attention); (c) consciousness as awareness (implicit vs. explicit learning and knowledge); and (d) consciousness as control (controlled vs. automatic processing) (p.11, with slight modifications in wording by the present author). Researchers generally accept the implicit and explicit distinction (N. Ellis, 1994; R. Ellis, 2009), 
but the dichotomy is not without controversy. ${ }^{2}$ Moreover, implicit and explicit learning do not neatly map onto the development of implicit and explicit knowledge. It is generally agreed that implicit knowledge is foundational for unrestricted and effortless development of both oral and written language, but researchers differ in their views of the interface between implicit/explicit knowledge (e.g., whether explicit knowledge can turn into implicit knowledge and vice versa, etc.) (R. Ellis, 2009). Early L1 vocabulary acquisition seems to be largely carried out incidentally (e.g., Wong-Fillmore, 1976), but explicit learning seems to play an increasing role as children grow. In order to attain a higher level of language register (e.g., literacy-related language), for example, explicit learning (as well as implicit learning) appears to be necessary, both in the case of $\mathrm{L}_{1}$ and $\mathrm{L} 2 / \mathrm{FL}$ (Hulstijn, 2015). Among adult L2/FL learners, it is generally reported that explicit learning is more effective (R. Ellis, 2008).

Lichtman (2013) provided some empirical evidence indicating that the bias toward explicit learning among adults may be due to the fact that older learners tend to receive more explicit instruction. Adolescent learners (age 14-17) in Lichtman's study who received the same type of implicit instruction as children (age 8-12) performed as well as the younger learners on tasks that were intended to capture implicit knowledge, whereas adolescent learners who received explicit instruction outperformed the younger children in tasks tapping explicit knowledge. In other words, learners' dependence on implicit or explicit learning, at least to some degree, may be an artifact of the types of instruction that they receive.

While the type of instruction plays a role, there is ample evidence showing that children and older learners show some differences in their preferred vocabulary learning strategies. Such differences in preferred strategies can be attributed to various factors, including cognitive maturity and linguistic and general knowledge associated with experience. Researchers have reported, for example, that children have a great dependence on formulaic language (chunks of words) (e.g., Hakuta, 1974; Huang \& Hatch, 1978; Wong-Fillmore, 1976; Yoshida, 1978). Children begin by attending to formulaic sequences in utterances, using them as unanalyzed wholes for the purpose of communication. As they advance their cognitive maturity and accumulate experiences, however, "the form-meaning combinations which they pick out of input are stored separately yet overlap in memory, and provide a source of growing or emergent grammar through subconscious cognitive processes on various levels, forming schematic patterns which eventually become available for analysis" (Wood, 2015, p.71). In other words, while the original multiword formats are stored in children's memory and

2. Some researchers have challenged the dichotomous approach to implicit and explicit learning. See, for example, Hulstijn (2015) for his continuum of conscious-unconscious view. 
retained for communicative purposes, children also eventually segment and analyze the chunks syntactically and semantically, and such processes will contribute to their language competence.

Research on the role of formulaic sequences among adult L2/FL learners remains limited; however, what research there is has shown that adult learners, particularly those who learn an L2/FL in a naturalistic context, also depend on formulaic sequences, but to a lesser degree than do children (e.g., Schmidt, 1983). In addition, adult learners appear to show substantial individual differences in their use of formulaic sequences due to various factors, including their learning environments, cognitive and learning styles, the combination of $\mathrm{L}_{1}$ and $\mathrm{L}_{2} / \mathrm{FL}$, and communicative motivation. Moreover, according to Wood (2015), unlike children, adult learners are less likely to analyze and segment formulaic sequences. Instead, adult learners can better make use of their greater lexical knowledge in L1 and richer conceptual knowledge and experience than children when they learn L2/FL vocabulary. It is important to note, however, that $\mathrm{L} 1$ knowledge does not necessarily facilitate L2/FL vocabulary development; it can have both positive and negative effects (Wolters, 2006, for a case of collocation development).

In sum, vocabulary learning is a complex process. Having an additional language influences L2/FL learning among children. While the basic mechanism for learning vocabulary appears to be the same between monolingual and bilingual children, various environmental factors that bilingual children are uniquely exposed to also influence both the amount and types of vocabulary that they learn in each of their languages, their rates of vocabulary growth, and their vocabulary learning strategies. Similarly, age plays an important role in L2/FL vocabulary learning, but many questions remain unanswered. Despite a widely held assumption among the general public that "the earlier, the better" in language learning, when it comes to vocabulary learning, we know little about how one's vocabulary learning is influenced by the onset of learning. We also have insufficient understanding of how implicit and explicit learning take place and how such learning may change over time among young L2/FL learners.

\section{Studies on young L2/FL learners' vocabulary instruction}

While there is a substantial body of research on vocabulary instruction among monolingual L1 children (including monolingual L1 children with language impairment), empirical research among young L2/FL learners remains limited. Considering that the basic mechanisms of vocabulary learning are the same for monolingual and bilingual children (as noted above), it is not too surprising that the interventions examining young L2/FL learners have been largely similar to 
those identified as being effective in L1 monolingual contexts. But at the same time, additional attention is necessary for specific needs and preferred learning styles and strategies of young L2/FL learners because of their unique environmental and age-specific elements, as mentioned previously.

A few meta-analyses and narrative reviews conducted among monolingual L1 children have identified a number of effective vocabulary interventions. They can be characterized as: (a) ensuring frequent and repeated exposure to the word; (b) providing children with explicit definitions and context-rich meanings of the word; and (c) creating opportunities for engaging in discussions and interactions with others about the word (e.g., Marulis \& Neuman, 2010; Mol, Bus, \& de Jong, 2009; Stahl \& Fairbanks, 1986; Steele \& Mills, 2011). In the subsections below, I use these characteristics as a guide when examining the research on vocabulary instruction, while at the same time paying attention to specific needs or characteristics of young L2/FL learners. Because a number of recent interventions incorporate multimodal strategies, relying on technology in particular, I added a fourth intervention type in this review: (d) using multimodal strategies, including technology. In general, most vocabulary interactions work equally well or even better with young L2/FL learners than with monolingual L1 learners, but the effects vary according to various intervention-related and individual factors.

\subsection{Ensuring frequent and repeated exposure}

First, young L2/FL learners, as well as monolingual L1 learners and older L2 learners, benefit from encountering target words repeatedly in multiple contexts (e.g., Biemiller \& Boote, 2006; Silverman, 2007a). However, in instructional settings, incidental vocabulary learning among L2/FL children may not occur with the same magnitude as monolingual L1 children. In the L1 acquisition research, fast mapping - a mental mechanism in which children can learn a new word through a single exposure or just a few exposures to the word in question - is well-known (Clark, 1993). Rohde and Tiefenthal (2000) examined whether fast mapping was observed in L2/FL among English-learning German children (age 3-6) and compared their vocabulary learning with that of their monolingual German-speaking peers (in their L1). The result indicated that, while incidental vocabulary learning after brief encounters was greater in L1, it also happened in L2/FL. Interestingly, however, the authors observed that when the children were learning L2/FL words, they tended not to be able to remember the exact objects that were labeled, but they could identify the semantic field that the target object belonged to; thus, the authors described such learning as "partial mapping" (p.167). The authors stated that "L1 and L2 lexical acquisition are not fundamentally different but that novel English words were less salient than novel German labels" (p.167). One could 
argue that "partial mapping" - partial detection of the target meaning - is a common phenomenon even among L1-learning children (e.g., Elley, 1989, for a case of school-age children); the basic process is the same whether children are learning an L1 or an L2/FL. Due to differences in the quality and quantity of input, however, L2/FL-learning children may need more refinements on how to identify meaning. As the authors indicated, social context may have explained the result as well; the children in their study might have been less attentive to English (their L2) because it was used only in the preschool context.

In order to enhance young learners' vocabulary development in instructional settings, repeated uses of input-based tasks - tasks that do not require spoken or written production (i.e., speaking and writing) - appear to be effective even among children who have relatively limited exposure to the target language outside of the classroom. Task-based instruction employed in classrooms is generally accompanied by some productions. Working with 6-8-year-old Japanese children who were learning English in a private language program, Shintani (2011) compared the vocabulary learning resulting from input-based tasks (i.e., listening) and output-based tasks (i.e., speaking) over 6 weeks. She found that the inputbased tasks were equally effective as production-based tasks both in terms of receptive and productive vocabulary learning. Even though the input-based tasks did not require the children to produce English, Shintani argued that the inputbased tasks seemed to provide them with rich interactional opportunities (even richer opportunities than the production-based tasks), and that such interaction might have contributed to the positive effect in their vocabulary learning, not only for receptive knowledge but also productive knowledge. Lin (2014) examined the effect of repeated exposure to teachers' read-aloud stories among fourth-grade English learners in Taiwan. Lin found a positive effect; on average, the children learned half of the target words by the third exposure. The positive results were obtained from both higher- and lower-proficiency students, but the effect was greater among the higher-proficiency group.

Book reading at home accompanied by book reading at school was found to facilitate children's L2 vocabulary even though the reading at home was conducted in both their L1 and their L2. Working with lower income Hmong- and Spanishspeaking preschool children learning English in the United States, Roberts (2008) implemented two 6-week sessions of home book reading; in the first session, the children were randomly assigned to book reading at home in either their L1 or L2, and they switched the language in the second session. Roberts found that the children showed significant gains by combining book reading at home and school. Most importantly, home book reading in L1 accompanied by the same book reading in L2 at school showed more vocabulary gains than the home book reading in L2 prior to the same book reading in L2 at school. After reading books in their 
familiar language, the children could construct meaning in the stories more easily and deeply, and such contextual supports might have facilitated greater gains in vocabulary knowledge in L2. Additionally, caregivers had greater involvement in their children's book reading in L1 than in L2, which means that the children had more support overall.

\subsection{Providing explicit word definitions and meanings in context}

As mentioned, implicit vocabulary learning occurs among young L2/FL learners, but research has indicated that both explicit and implicit teaching is necessary, especially in instructional settings or in relatively limited-input environments. A number of studies found that it is effective to explicitly explain words by referring to their parts of speech, roots, and morphological elements, and to offer clear definitions of words and example usages (Biemiller \& Boote, 2006; Carlo et al., 2004; Collins, 2010). Critically, such explicit instruction has to be carried out in context; this is perhaps one of the reasons why many vocabulary interventions for young learners have been conducted through storytelling and book reading.

In addition to offering word definitions, actively engaging children in analyses of word meaning appears to be more effective than merely helping relate new words to story contexts or children's personal experiences. Silverman (2007a), for example, compared three strategies during storybook read-alouds among preschool children (including English-as-L2 language learners). The three strategies were contextual instruction, analytical instruction, and anchored instruction. In the contextual instruction, the children discussed word meaning as they related to the stories as well as to personal experiences. In the analytical instruction, in addition to the word meaning in context, they had opportunities to use the target words in various contexts outside of the stories and examined the appropriateness of their use. In the anchored instruction, the children were attentive to phonological and orthographical aspects of words (i.e., the association between the sound and the form) in addition to the meaning. The study found that the analytical and anchored instructions were more effective, in receptive vocabulary learning in particular, than the contextual instruction both in terms of immediate and delayed effects. Silverman speculated that the analytical instruction would be particularly effective for L2 learners (and monolinguals with lower socioeconomic status), although their performance was not disentangled from that of the monolingual speakers in this study. In Silverman (2007b), she compared the effectiveness of an intervention that combined the analytical and anchored instructions described above for L2 learners and monolingual English speakers. The intervention was effective for both groups. Importantly, although the initial vocabulary score was lower among L2 learners, their growth rate was larger than the growth 
rate of their monolingual English peers after controlling for the effect of SES and the concept of print (i.e., children's knowledge about how printed reading materials, such as books, work, which is considered to be an important predictor for reading success).

Although many vocabulary interventions were effective for both $\mathrm{L} 2 / \mathrm{FL}$ and monolingual children, others were specifically designed for bilingual children. One such intervention was the use of learners' L1. Lugo-Neris, Jackson, Goldstein (2010) worked with English-Spanish bilingual children (ages 4-6) in the United States, conducting a shared storybook reading in L2 with explicit vocabulary explanations either in the children's L1 or L2. The results showed that the explanations offered in the children's L1 led to greater gains in their naming, receptive vocabulary knowledge, and productive definitions than the intervention offered in L2. As one may expect, the children who had developed high proficiency in at least one language benefited more than those who had not had.

How L1 is used in an intervention does matter, however. Merely offering translation in children's L1 seems to have a limited effect. Ulanoff and Pucci (1999) compared two intervention strategies (a concurrent translation method and a preview - review method) administered to third-grade Spanish-speaking children learning English. In the concurrent translation method, translation in the children's L1 was offered in advance of the reading. In the preview - review method, background information as well as explanations of difficult words were offered in L1 before the reading, and major points were revisited again in L1 after the reading. The preview - review method was found to be more effective than the concurrent method (the concurrent method showed lower gains even compared with the control group). Knowing that the story would be translated into L1 in advance somehow might have discouraged children from paying attention to the story in L2. Tonzer, Lotto, and Job (2009) revealed a complicated interaction among two types of vocabulary teaching (L1-mediated learning and picture-mediated learning), word status (cognate or not), and age (age 9 or 13) among Italian students learning both English and German at school. The study found that the picture method was more effective than the L1-mediated method overall. But a closer look at the data revealed that the L1 word-mediated method showed relatively stronger effects when learning cognates and that such effects were larger among older students, particularly in their stronger L2 (i.e., English in this case).

Finally, efforts also have been made to teach word-learning strategies to young L2/FL learners along with explicit word instruction. With the aim of enhancing fifth graders' academic vocabulary, Carlo and colleagues (2004) implemented a 15-week intervention in which carefully selected target words were explicitly instructed (e.g., instruction focusing on the depth of meaning, polysemy, morphological and cross-linguistic information, spelling and pronunciation) with 
repeated exposures to these words in bilingual texts. In addition, word-learning strategies (e.g., how to infer word meaning in context, how to make use of morphological cues and cognates, how to use glossaries, etc.) were also explicitly taught. The results showed that the intervention was as highly effective for L2/FL learning children as for their monolingual counterparts. Similarly, Bedore, Peña, and Boerger (2010) indicated that teaching L2/FL children both aural and visual strategies for recognizing cognates facilitated their L2 vocabulary learning.

\subsection{Creating opportunities for discussion and interaction}

In addition to the provision of explicit definitions and meanings of words in context, L2/FL children's vocabulary learning is likely facilitated by having conversations about words and their meanings with their teachers and peers during and after storytelling and shared reading (e.g., Atay \& Kurt, 2006; Chlapana \& Tafa, 2014). However, how precisely interactions with teachers and peers contribute to young learners' L2/FL vocabulary learning is not well understood due to the limited research conducted among L2/FL children so far.

Questioning children on target words and the word meanings can facilitate both their receptive and productive word development, but how adults ask questions or interact with children seems to matter. Blewitt, Rump, Shealy, and Cook (2009), argued that cognitively high- and low-demand questions ${ }^{3}$ may help children's word learning in different ways, although their study was based on monolingual L1 preschool children. Blewitt et al. found that when the teachers used what the researchers described as a scaffolding-like dialogic style - namely, starting with cognitively low demand questions and gradually introducing higher demand questions - this approach did facilitate the children's word definition abilities more compared with conditions where either high- or low-demand questions (but not a combination of both types) were offered to the children. The authors speculated that low-demand questions may familiarize the children with the target words and help them maintain their attention to the words in question. In contrast, high-demand questions may assist children to access more elaborated word meaning and usage but only after they become familiar with the word. Whether this is indeed the case - and whether the same process happens among young L2/ FL learners as well as L1 learners - awaits empirical investigation.

3. Cognitively high-demand questions ask children to distance themselves from the immediate story contexts and encourage them to make inferences, such as about the characters' feelings and the coherence of the story line. Questions concerning simple descriptions of scenes and pictures tend to be low in cognitive demand. 
In reality, teachers ask a variety of questions and engage in a variety of interactions during their instruction. Connor, Morrison, and Slominski (2006) observed a number of preschool classrooms (mostly composed of monolingual L1 children but with a small portion of L2 learners) in a large school district in the United States, and reported substantial variability in both types and amount of language and literacy-related activities that the children had the opportunity to experience in class. Importantly, children receiving the same instruction seemed to have different learning opportunities. According to Connor et al., children who initially had stronger vocabulary knowledge benefited from both explicit code- and meaning-focused instruction led by teachers, whereas children with smaller vocabularies benefited more from playing with teachers and peers, or implicit, meaning-focused activities. It would be worth investigating in detail what happens in the interaction during children's play. Shintani (2012) looked into interaction during oral input-based tasks administered to 6-year-old Japanese children learning English and found that the tasks yielded rich interactional opportunities and meaningful feedback. Shintani (2012) extracted the following three characteristics, which presumably contributed to the children's incidental word learning: (a) opportunities to use L2 for multiple purposes; (b) opportunities for children to have some control over their interaction; and (c) receiving referential questions (i.e., questions that the speaker does not know the answer to) rather than display questions (i.e., questions that the speaker already knows the answer to; also referred to as known questions) by the teacher (p.264).

Children learning an L2/FL negotiate meaning during interaction with others, and the process of negotiating meaning appears to play an important role in incidental vocabulary learning. Limited studies to date suggest that negotiating for meaning aids children's comprehension but that the extent to which active engagement for meaning negotiation directly facilitates their incidental learning remains unclear. For example, whereas Ellis and Heimbach (1997) found a relatively limited effect of active engagement for meaning negotiation, Shintani (2012) and Shintani and Ellis (2014) showed more promising results. It's likely that there are substantial individual differences as well. In any event, more research on interaction among young L2/FL learners would greatly enhance our understanding of the process of their vocabulary learning.

\subsection{Using multimodal approaches}

Providing children with information through multiple means, including music, songs, pictures, physical activities, and gestures, has been considered an effective way to support their learning, including their L2/FL learning. For example, in the Total Physical Response approach (Asher, 2009), an approach still frequently used 
in young L2/FL classrooms, learners are asked to respond to their teachers' or peers' commands (e.g., "stand up!") by demonstrating physical actions. We also have some evidence showing that bilingual children are better than their monolingual counterparts at using a speaker's referential cues (e.g., eye gazing and pointing) to narrow down the meaning of words in fast mapping (Yow et al., 2017). In recent years, multimodal approaches using technology have gained growing attention as well.

Songs and music have long been a popular instructional strategy for young L2/FL learners as well as young L1 learners. It is often believed that songs and music motivate children to learn the target language, and that the rhythmic and structural properties of songs and music assist children's lexical memory (Davis, 2017). Despite the popularity of songs and music in young learners' language education, however, how and why songs and music promote children's L2/FL vocabulary learning is not totally clear either theoretically and empirically. No agreed-upon theoretical justification for the use of music and songs has been presented. Recent neuro-based research concerning the relationship between music and language processing in the brain has not provided us with a clear picture of the roles of songs and music in young L2/FL language development, including vocabulary learning; this may be partially because the research has mostly been done among monolingual L1 speakers (Ludke, 2010). Behavioral investigations of effectiveness of songs and music in children's L2/FL learning also have been limited. Coyle and Gracia (2014) implemented three 30 minute-instructional sessions using a popular children's song targeting 5-year-old Spanish-speaking children learning English as an L2/FL. The result indicated that the input through the song was effective for their receptive vocabulary learning but not for their productive vocabulary learning. Davis and Fan (2016) taught English-learning kindergarteners in China five short English phrases composed of 4-8 words through songs, choral repetition, or no special aid (control). The children's performance, measured by a picture description task, indicated that learning through both songs and choral repetition was more effective than the control condition. Leśniewska and Pichette (2016) found that both songs and stories helped French-speaking English-learning children (35-59 months) recall animate vocabulary items regardless of their L1 vocabulary levels. With the limited empirical research available, it is hard to reach any conclusions about the use of songs and music in L2/FL vocabulary instruction for young learners. Studies of this topic implemented songs and music to different groups of children in various ways and for various lengths of time. Outcome measures were all different. The interventions were often accompanied by other components, such as gestures, pictures, and activities during and after the music. It is therefore not clear what, exactly, contributed to the results. 
Vocabulary learning accompanied by some types of body movements is also widely believed to be effective. Indeed, a large number of studies show positive relationships between physical exercise and cognitive functioning and academic performance among children (see Tomporowski, Davis, Miler, \& Naglieri, 2008 for a review of such studies). Here again, the precise mechanism of the relationship remains unclear. Learning activities involving bodily movement, including gestures, result in enhancing one's memory and retention, possibly because bodily movements provide additional aids for creating better mental representation (Paas \& Sweller, 2012; Pesce et al., 2009). This idea is highly plausible given a growing number of neuroscientific studies uncovering that lexical representation in our brains is experiential based, which in turn is connected to the body (Macedonia, 2014).

Tellier (2008) examined whether a combination of gestures and pictures would be more effective than presenting pictures only when teaching English words to monolingual French-speaking preschool children (age 4-5) in four sessions. The results showed that, compared with the picture-only condition, the children acquired both receptive and productive knowledge of the target words better if they saw and produced gestures while repeating the words. This study highlighted the importance of reproducing gestures while vocalizing words in order to enhance children's lexical production (using words) as well as their comprehension (understanding words). It is important to note, however, that the children's performance varied greatly across different target items. Porter (2016) similarly introduced French words to English-speaking children (age 4-7) in three sessions and also found that the combination of gestures with pictures facilitated the children's recall of the target words better than simply presenting pictures only; however, the effect was found only in an immediate recall, and not in a delayed recall (2 weeks after the intervention).

While some gestures may be more salient for learners than others, the effect of gestures also varied according to the learners' characteristics. Rowe, Silverman, and Mullan (2013) examined the effect of three presentation types when teaching words in a novel language to preschool children: (a) words only; (b) words and gestures; and (c) words and pictures. Comprehension-based assessments indicated that bilingual children with high L2 proficiency benefited most from the words-only condition in learning words in a novel language, whereas bilingual children with lower L2 proficiency benefited significantly from having additional aids (a combination of the gesture and picture conditions). This is a very interesting finding, suggesting that providing information through multiple channels may help less advanced students but potentially impede advanced learners. It may be possible that advanced learners have already developed effective 
strategies without depending on multiple modalities, which can be cognitively more taxing to process.

The preceding studies make it clear that more precise investigation is needed regarding the types of gestures used in interventions and how they are implemented. Apparently, not all gestures are equally effective. Gestures may be effective only for certain types of lexical representations or only when used in certain ways. Mavilidi and colleagues (2015) found that an integrated physical exercise condition (children enacted actions related to the targeted words) was more effective than a gesture condition for preschool children's L2/FL vocabulary learning. Toumpaniari, Loyens, Mavilidi, and Paas (2015) also reported that combining task-relevant physical activities and gestures was more effective than gestures only. Based on these findings, it seems likely that it is not the types of embodiments (gestures or physical activities) that influence effectiveness but rather how well body movements are matched with the target lexical mental representation or meaning.

Finally, using e-books and other technologies as visual and auditory aids has been found to be effective for young L2/FL learners (e.g., Verhallen \& Bus, 2010). Such technology-based aids are particularly effective if they are combined with mediation and scaffolding by teachers and other adults (Leacox \& Jackson, 2012). It may not be effective at all if no such adult mediation is provided (Uchikoshi, 2006). Again, it seems that not all technology-aided instruction works well for children's vocabulary learning under any conditions. The effectiveness varies depending on a variety of factors, including (a) types of words; (b) types of technology and programs (e.g., certain TV or video programs work but not others); (c) types of vocabulary knowledge targeted (receptive or productive knowledge); and (d) types of learners (age, proficiency levels, motivation/interests). As with gestures, technology-aided instruction appears to benefit less-proficient students more than higher-proficient students (e.g., Silverman \& Hines, 2009), although the precise mechanism explaining why additional modal aids through technology can work better with less-proficient students remains unclear.

In this section, major vocabulary interventions were identified and discussed. Although intervention studies among young L2/FL learners remain relatively limited, major interventions that have proven to be effective for L1-learning monolingual children also appear to work well (or even better) with L2/FL children. But at the same time, some interventions are specifically designed to account for the unique characteristics of children learning an L2/FL, including their L1 knowledge and various experiences associated with learning in more than one language. The effectiveness of interventions for L2/FL-learning children show variability depending on their individual factors as well as implementation- and contextualrelated factors. 


\section{Suggestions for future research}

As this review makes clear, research on teaching vocabulary to young L2/FL learners is still relatively limited. We have more questions than answers at this point. In this section, I address areas to explore further in order to inform practice.

\subsection{More detailed investigations concerning the interaction between intervention (both types and quality of interventions) and individual differences}

When researchers or teachers implement theoretically or experientially plausible instructional strategies, it is not surprising to find positive effects. What would be more informative is in-depth investigations of how interventions are implemented; namely, studies that concern the procedures and strategies of implementation. In addition, we need more research that disentangles the complicated interactional effects of various environmental, linguistic, and individual (both of teachers and learners) factors. We know that not all words are learned equally well; interactions between different strategies and the target lexical items need to be better understood. Similarly, not all books, stories, and songs are equally effective for everybody. If the books and stories do not match well with the children's developmental stages, motivation, and proficiency levels, they may not be as beneficial. As we have seen in Connor et al. (2006), children benefit differently under the same interventions. While some studies consider young L2/FL learners' proficiency levels (e.g., Rowe et al., 2013; Silverman \& Hines, 2009; ), the focus is usually only on the target language. More interventions should attend to children's entire linguistic repertoire in both languages (e.g., cross-linguistic awareness, preexisting knowledge on cognates, and bilingual peer networks, etc.). Various mediating variables should be identified and thoroughly examined in order to uncover the complex picture of reality.

We also need to better understand the precise mechanisms explaining how and why a certain vocabulary instruction works. Mapping instructional strategies and theoretical constructs (e.g., implicit and explicit learning) would be helpful. One possible way to uncover vocabulary learning mechanisms is to conduct deeper discourse analyses on interactions between teachers and children and among children. As we learned from Ulanoff and Pucci (1999), how teachers ask questions influences the L1 vocabulary learning of monolingual children. We continue to have a very limited understanding of the discourse or scaffolding strategies that work as mediators or facilitators for children's L2/FL vocabulary development. While some studies show different discourse patterns between child adult and child - child interactions, which provide different opportunities for L2/ 
FL learning (e.g., Butler \& Zeng, 2014; Peck, 1978; also see Oliver \& Mackey, 2003), with the exception of a few studies (e.g., Shintani, 2012, discussed above), little is understood about how such interactions contribute to children's vocabulary learning per se. Since it is possible that the effect of various types of interactional and scaffolding strategies may differ across age groups with different linguistic and world knowledge backgrounds, more research on children at different ages (older children in particular, since most vocabulary intervention studies concern preschool children) would be particularly informative. Finally, children engage in vocabulary learning not only in the classroom but also outside of the classroom; even in an FL-learning context, thanks to technology and other means, children are increasingly exposed to the target language, especially in the case of English. Therefore, the relationship between out-of-school and in-school learning would be a fruitful area of investigation.

\subsection{More considerations of outcome measures: What is the target} vocabulary knowledge and how do we measure it?

Researchers have had various, somewhat skewed, conceptualizations of what accounts for lexical knowledge as the target knowledge in their interventions. Although tasks requiring learners to match words (usually presented orally) with pictures have commonly been used as a measure, vocabulary knowledge means much more than simply connecting a given word with a meaning. And yet few studies have examined other aspects of vocabulary knowledge, such as rhythm and prosodic features of words, sound - form associations, metalexical awareness (e.g., phonological, morphological, and orthographical awareness), multiple meanings, and multiple usages and pragmatics in different contexts. The types of words that have been studied are limited as well. Targeted words have predominantly been nouns (concrete nouns, in particular) with words in other lexical categories receiving far less attention.

Systematic investigations of underlying processes of lexical learning among young L2/FL learners are rare. The research I reviewed is not always clear about the precise goal of the intervention: Do interventions aim at developing children's intentional vocabulary learning or incidental learning? Moreover, more attention needs to be paid to measurements in general: Is the targeted vocabulary knowledge captured appropriately in the measurement? A stronger theoretical justification for young L2/FL vocabulary learning is necessary as well: What are the roles of vocabulary interventions in young L2/FL learners' explicit and implicit vocabulary learning? While some researchers focus on the target words only, others may include nontarget words, claiming them as evidence of incidental learning. In the latter case, however, how the nontarget words were chosen in the measurement 
was usually unspecified. Curiously, since the 1970 s there has been little research on the effect of vocabulary interventions on L2/FL learners' formulaic language learning (e.g., Hakuta, 1974; Huang \& Hatch, 1978; Yoshida, 1978).

This review of the body of research on vocabulary instruction for young L2/ FL learners makes it clear how challenging it is to measure bilinguals' L1 and L2 vocabulary knowledge validly and reliably. Interpreting the results, therefore, often requires special caution. Many studies employed some type of standardized assessments, such as the Peabody Picture Vocabulary Test (PPVT, a standardized receptive vocabulary test of American English), that were developed for a specific language and normed based on a specific target population. Researchers often used a translated version of the original assessment to measure vocabulary knowledge in other languages, largely due to a lack of reliable measures in their target languages. However, translating the original assessment requires serious validity and reliability checks. Moreover, it is not uncommon among studies to use measurements that were not normed based on the same population as the focus groups in the studies (e.g., using PPVT for English-learning children in China to measure their English vocabulary knowledge). Sometimes relying on existing assessments is the only realistic option, particularly when a reliable and valid assessment is not available, but one needs to be mindful of its limitations and potential for misleading information even if researchers report an acceptable level of reliability among their participants. Indeed, Gibson, Jarmulowicz, and Oller (2018) showed that children's vocabulary knowledge profiles (gaps between receptive and productive knowledge in this study) varied greatly depending on standardized tests that were used, partially due to a lack of comparable normed scores in other languages.

Researcher-made assessments are not free from validity and reliability concerns, either. A meta-analysis by Marulis and Neuman (2010), which was conducted among monolingual L1 speaking prekindergarten and kindergarten children, reported on the potential for inflated results in studies using researcher-made outcome measures; compared with standardized assessments, the effect sizes for researcher-made assessments were larger. Although this finding is not surprising considering that the researcher-made assessments were more focused, it is important for researchers to be cautious about a potential measurement bias; using multiple measures is highly recommended. My review also indicates the need for researcher-made assessments to carefully attend to age-related challenges that children may have. Vocabulary is closely related to concepts; therefore, the targeted words should be appropriate for children's cognitive developmental levels and experiences. Some assessments were administered in a highly decontextualized manner (e.g., words were offered in stories, namely in context, but the assessment was administered in a mechanical, out- 
of-context fashion) or heavily depended on children's verbal responses (e.g., verbally explaining word definitions). In the latter case, the procedures of the assessment could be cognitively too taxing depending on the age of the children (as well as the children's general language proficiency level in their L1 and/ or L2). Older children's advantage in vocabulary gains over younger children might have been at least partially due to artifacts of the assessment format and procedure. It is also important to keep in mind that children, younger children in particular, are sensitive to pragmatic oddness that can be created in certain assessment contexts. Carpenter, Fujii, and Kataoka (1995) reported that during a picture-naming assessment - a very popular type of assessment for children children age 5-10 who were learning an L2/FL were puzzled when the teachers administering the assessment were also looking at the pictures they were asking the children to name (which is the often the case), resulting in shyness and avoidance of answers. In an ordinary context, if a person knows what the pictures refer to, there would be no need to ask others to name them. Indeed, children need to be socialized into assessment culture (Butler \& Zeng, 2014).

Similar measurement challenges are associated with capturing the depth of bilingual children's vocabulary knowledge (i.e., how much one knows about a word), and few vocabulary intervention studies investigated depth of knowledge in a systematic fashion. One's vocabulary knowledge can be conceptualized as a continuum rather than a dichotomy (knowing vs. not knowing), ranging from never having seen the term before to fully knowing its meaning and usage. ${ }^{4}$ To measure depth of vocabulary knowledge, interviews or self-judgments are often used for adult learners. However, such techniques may not be appropriate for young learners, again depending on their cognitive maturity and experience with self-evaluations. Due to bilingual children's variability of learning contexts and their use of more than one language, they are more likely to have varied cultural and pragmatically specific ways of understanding and using lexicons. Such varied knowledge and use of lexicons may potentially influence their self-evaluation and performance. Behavioral observations and/or multiple tasks in a longitudinal investigation might be necessary to capture young learners' depth of vocabulary knowledge.

In this section, I offered some suggestions for future research in order to better connect research and practice. I mainly focused on two issues. First, we need more thorough investigations concerning intervention processes and interaction during the intervention in relation to various individual and contextual variables. Instead of examining whether or not a certain intervention is effective, we need

4. There are different views on how to conceptualize depth of vocabulary knowledge and its relationship with the size of vocabulary knowledge (Schmitt, 2014). 
greater attention to conditions and variables that are influential over both the intervention processes and outcome. We also need more effort to uncover underlying mechanisms explaining varying degrees of success of interventions. Second, we need more refined conceptualizations of lexical knowledge among young L2/ FL learners and appropriate measurements to capture such knowledge. Multiple approaches to collecting data while paying sufficient attention to young L2/FL learners' age-related characteristics and their specific needs are called for.

\section{Conclusion}

My goal in reviewing major studies of vocabulary instruction targeting young L2/ FL learners - studies that are scattered across multiple related fields - is to identify effective approaches that are theoretically sound and empirically proven. I identified four major characteristics of effective vocabulary instruction for practitioners: (a) ensuring frequent and repeated exposure to the target words (and nontarget words); (b) providing explicit definitions and meanings in context; (c) creating opportunities for discussions and interactions; and (d) using multimodal approaches to teach vocabulary. While the basic vocabulary-learning mechanisms seem to be the same for both monolingual L1 learners and young L2/FL learners, I discussed some L2/FL-specific strategies that teachers can adopt, such as using learners' L1 and L1-related metaknowledge (e.g., cognates). I also discussed agerelated specific considerations that are necessary for young learners, including the importance of both implicit and explicit learning.

Empirical research concerning young L2/FL learners is still relatively underexplored, leaving researchers and educators with more questions than answers. Previous research suggests that the effectiveness of vocabulary intervention is influenced by various individual (e.g., children's age, proficiency levels in L1 and L2), contextual (e.g., types of target vocabulary), and measurement-related factors (e.g., validity and reliability of vocabulary assessments). Through their interactions with students, teachers are at the forefront of identifying and negotiating such factors with their students. As suggested by Ellis and Shintani (2014), we should take teachers' insights and pedagogical challenges as a starting point of instructed SLA research, instead of starting with research and thinking about pedagogical implications out of the research findings. More direct collaborations between researchers and teachers would be beneficial for enhancing children's L2/ FL learning in instructional settings. To further advance our understanding, we also need more close communication among researchers who are working in different contexts and academic disciplines. 


\section{References}

Abrahamsson, N., \& Hyltenstam, K. (2009). Age of onset and nativelikeness in second language. Language Learning, 59(2), 249-306. https://doi.org/10.1111/j.1467-9922.2009.00507.x

Asher, J. (2009). Learning another language through actions: The complete teacher's guidebook (7th ed.). Los Gatos, CA: Sky Oaks Productions.

Atay, D., \& Kurt, G. (2006). Elementary school EFL learners' vocabulary learning: The effects of post-reading activities. The Canadian Modern Language Review, 63(2), 255-273. https://doi.org/10.3138/cmlr.63.2.255

Bedore, L., Peña, E., \& Boerger, K. (2010). Ways to words: Learning a second language vocabulary. In M. Schatz \& L. Wilkinson (Eds.), The education of English language learners: Research to practice (pp. 87-107). New York, NY: Guilford Press.

Bialystok, E., Luk, G., Peets, K. F., \& Yang, S. (2010). Receptive vocabulary differences in monolingual and bilingual children. Bilingualism: Language and Cognition, 13(4), 525-531. https://doi.org/10.1017/S1366728909990423

Biemiller, A., \& Boote, C. (2006). An effective method for building meaning vocabulary in primary grades. Journal of Educational Psychology, 98(1), 44-62.

https://doi.org/10.1037/0022-0663.98.1.44

Blewitt, P., Rump, K., Shealy, S. E., \& Cook, S. A. (2009). Shared book reading: When and how questions affect young children's word learning? Journal of Educational Psychology, 101(2), 294-304. https://doi.org/10.1037/aoo13844

Bosch, L., \& Ramon-Casas, M. (2014). First translation equivalent in bilingual toddlers' expressive vocabulary: Does form similarity matter? International Journal of Behavioral Development, 38(4), 317-322. https://doi.org/10.1177/0165025414532559

Butler, Y.G. (2016). Age factors in language acquisition. In M. Minami (Ed.), Handbook of Japanese applied linguistics (pp. 67-96). Berlin: Mouton de Gruyter. https://doi.org/10.1515/9781614511830-007

Butler, Y.G., \& Zeng, W. (2014). Young foreign language learners' interactions during taskbased paired assessment. Language Assessment Quarterly, 11(1), 45-75. https://doi.org/10.1080/15434303.2013.869814

Byers-Heinlein, K., \& Fennell, C. T. (2013). Perceptual narrowing in the context of increased variation: Insights from bilingual infants. Developmental Psychobiology, 56(2), 274-291. https://doi.org/10.1002/dev.21167

Byers-Heinlein, K., \& Werker, J.F. (2013). Lexicon structure and the disambiguation of novel words: Evidence from bilingual infants. Cognition, 128, 407-416. https://doi.org/10.1016/j.cognition.2013.05.010

Carlo, M.S., August, D., McLaughlin, B., Dressler, C., Lippman, D. N., Lively, T. J., \& White, C. E. (2004). Closing the gap: Addressing the vocabulary needs of Englishlanguage learners in bilingual and mainstream classrooms. Reading Research Quarterly, 39, 188-215. https://doi.org/10.1598/RRQ.39.2.3

Carpenter, K., Fujii, N., \& Kataoka, H. (1995). An oral interview procedure for assessing second language abilities in children. Language Testing, 12(2), 158-181. https://doi.org/10.1177/026553229501200202

Chlapana, E., \& Tafa, E. (2014). Effective practices to enhance immigrant kindergarteners' second language vocabulary learning through storybook reading. Reading and Writing, 27, 1619-1640. https://doi.org/10.1007/s11145-014-9510-7 
Clark, E. (1993). The lexicon in acquisition. Cambridge: Cambridge University Press. https://doi.org/10.1017/CBO9780511554377

Collins, M.F. (2010). ELL preschoolers' English vocabulary acquisition from storybook reading. Early Childhood Research Quarterly, 25, 84-97. https://doi.org/10.1016/j.ecresq.2009.07.009

Connor, L. M., Morrison, F. J., \& Slominski, L. (2006). Preschool instruction and children's emergent literacy growth. Journal of Educational Psychology, 98(4), 665-689. https://doi.org/10.1037/0022-0663.98.4.665

Coyle, Y., \& Gracia, R. G. (2014). Using songs to enhance L2 vocabulary acquisition in preschool children. ELT Journal, 68(3), 276-285. https://doi.org/10.1093/elt/ccuo15

Davis, G. M. (2017). Songs in the young learner classroom: A critical review of evidence. ELT Journal, 71(4), 445-455.

Davis, G. M., \& Fan, W. (2016). English vocabulary acquisition through songs in Chinese kindergarten students. Chinese Journal of Applied Linguistics, 39(1), 59-71. https://doi.org/10.1515/cjal-2016-0004

Davison, D., \& Tell, D. (2005). Monolingual and bilingual children's use of mutual exclusivity in the naming of whole objects. Journal of Experimental Child Psychology, 92(1), 25-45. https://doi.org/10.1016/j.jecp.2005.03.007

De Houwer, A. (2009). Bilingual first language acquisition. Bristol: Multilingual Matters.

Diesendruck, G. (2005). The principles of conventionality and contrast in word learning: An empirical examination. Developmental Psychology, 41(3), 451-463.

https://doi.org/10.1037/0012-1649.41.3.451

Elley, W. B. (1989). Vocabulary acquisition from listening to stories. Reading Research Quarterly, 24(2), 174-187. https://doi.org/10.2307/747863

Ellis, N. (1994). Introduction: Implicit and explicit language learning - An overview. In N.C. Ellis (Ed.), Implicit and explicit learning of languages (pp. 1-31). London: Academic Press.

Ellis, R. (2008). The study of second language acquisition (2nd ed.). Oxford: Oxford University Press.

Ellis, R. (2009). Retrospect and prospect. In R. Ellis, S. Loewen, C. Elder, R. Erlam, J. Phip, \& $\mathrm{H}$. Reinders (Eds.), Implicit and explicit knowledge in second language learning, testing and teaching (pp. 335-353). Bristol: Multilingual Matters. https://doi.org/10.21832/9781847691767-016

Ellis, R., \& Heimbach, R. (1997). Bugs and birds: children's acquisition of second language vocabulary through interaction. System, 25(2), 247-259. https://doi.org/10.1016/So346-251X(97)0oo12-2

Ellis, R., \& Shintani, N. (2014). Exploring language pedagogy through second language acquisition research. London: Routledge.

Fennell, C. T., \& Byers-Heinlein, K. (2014). You sound like Mommy: Bilingual and monolingual infants learn words best from speakers typical of their language environments. International Journal of Behavioral Development, 38(4), 309-316. https://doi.org/10.1177/0165025414530631

Fennell, C. T., Byers-Heinlein, K., Werker, J. F. (2007). Using speech sounds to guide word learning: The case of bilingual infants. Child Development, 78(5), 1510-1525. https://doi.org/10.1111/j.1467-8624.2007.01080.x

Fennell, C., \& Lew-Williams, C. (2018). Early bilingual word learning. In G. Westermann \& N. Mani (Eds.), Early word learning (pp. 110-122). London: Routledge. 
Gibson, D. A., Jarmulowicz, L., \& Oller, D. K. (2018). Difficulties using standardized tests to identify the receptive expressive gap in bilingual children's vocabularies. Bilingualism: Language and Cognition, 21(2), 328-339. https://doi.org/10.1017/S1366728917000074

Goodrich, J.M., \& Lonigan, C. J. (2018). Development of first- and second-language vocabulary knowledge among language-minority children: Evidence from single language and conceptual scores. Journal of Child Language. https://doi.org/10.1017/S0305000917000538

Granena, G., \& Long, M. (2012). Age of onset, length of residence language aptitude, and ultimate L1 attainment in three linguistic domains. Second Language Research, 29(3), 311-343. https://doi.org/10.1177/0267658312461497

Hakuta, K. (1974). Prefabricated patterns and the emergence of structure in second language acquisition. Language Learning, 24, 287-297. https://doi.org/10.1111/j.1467-1770.1974.tboo509.x

Hoff, E., Core, C., Place, S., Rumiche, R., Señor, M., \& Parra, M. (2012). Dual language exposure and early bilingual development. Journal of Child Language, 39(1), 1-27. https://doi.org/10.1017/S0305000910000759

Houston-Price, C., Zoe, C., \& Raviglione, E. (2010). Language experience shapes the development of the mutual exclusivity bias. Infancy, 15, 125-150. https://doi.org/10.1111/j.1532-7078.2009.00009.x

Huang, J., \& Hatch, E. (1978). A Chinese child's acquisition of English. In E. M. Hatch (Ed.), Second language acquisition: A book of readings (pp. 118-131). Rowley, MA: Newbury House.

Hulstijn, J.H. (2015). Explaining phenomena of first and second language acquisition with the constructs of implicit and explicit learning: The virtues and pitfalls of a two-system view. In P. Rebuschat (Ed.), Implicit and explicit learning of language (pp. 25-46). Amsterdam: John Benjamins. https://doi.org/10.1075/sibil.48.02hul

Leacox, L., \& Jackson, C. W. (2012). Spanish vocabulary-bridging technology-enhanced instruction for young English language learners' word learning. Journal of Early Childhood Literacy, 14(2), 175-197. https://doi.org/10.1177/1468798412458518

Lervåg, A., \& Aukrust, V.G. (2010). Vocabulary knowledge is a critical determinant of the difference in reading comprehension growth between first and second language learners. The Journal of Child Psychology and Psychiatry, 51(5), 612-620. https://doi.org/10.1111/j.1469-7610.2009.02185.x

Leśniewska, J., \& Pichette, F. (2016). Songs vs. stories: Impact of input sources on ESL vocabulary acquisition by preliterate children. International Journal of Bilingual Education and Bilingualism, 19(1), 18-34. https://doi.org/10.1080/13670050.2014.960360

Lichtman, K. (2013). Developmental comparisons of implicit and explicit language learning. Language Acquisition, 20, 93-108. https://doi.org/10.1080/10489223.2013.766740

Lin, L.-C. (2014). Learning word meanings from teachers' repeated story read-aloud in EFL primary classrooms. English Language Teaching, 7(7), 68-81.

https://doi.org/10.5539/elt.v7n7p68

Ludke, K. M. (2010). Songs and singing in foreign language learning (Unpublished doctoral dissertation). Retrieved from <https://www.era.lib.ed.ac.uk/handle/1842/5500>

Lugo-Neris, M., Jackson, C. W., \& Goldstein, H. (2010). Facilitating vocabulary acquisition of young English language learners. Language, Speech, and Hearing Services in Schools, 41, 314-327. https://doi.org/10.1044/0161-1461(2009/07-0082)

Macedonia, M. (2014). Bringing back the body into the mind: Gestures enhance word learning in foreign language. Frontiers in Psychology, 5, 1-6. https://doi.org/10.3389/fpsyg.2014.01467 
MacLeod, A.A.N., Castellanos-Ryan, N., Parent, S., Jacques, S., \& Séguin, J. R. (2018). Modeling vocabulary development among multilingual children prior to and following the transition to school entry. International Journal of Bilingual Education and Bilingualism. https://doi.org/10.1080/13670050.2016.1269718

Mancilla-Martinez, J., \& Lesaux, N. K. (2011). The gap between Spanish speakers' word reading and word knowledge: A longitudinal study. Child Development, 82(5), 1544-1560. https://doi.org/10.1111/j.1467-8624.2011.01633.x

Marchman, V.A., Martínez, L.Z., Hurtado, N., Grüter, T., \& Fernald, A. (2017). Caregiver talk to young Spanish-English bilinguals: Comparing direct observation and parent-report measures of dual-language exposure. Developmental Science, 20. https://doi.org/10.111/desc.12425

Markman, E. M., \& Wachtel, G. F. (1988). Children's use of mutual exclusivity to constrain the meaning of words. Cognitive Psychology, 20, 121-157. https://doi.org/10.1016/0010-0285(88)90017-5

Marulis, L. M., \& Neuman, S. B. (2010). The effects of vocabulary intervention on young children's word learning: A meta-analysis. Review of Educational Research, 80(3), 300-335. https://doi.org/10.3102/0034654310377087

Mattock, K., Polka, L., Rvachew, S., \& Krehm, M. (2010). The first steps in word learning are easier when the shoes fit: Comparing bilingual and monolingual infants. Developmental Science, 13(1), 229-243. https://doi.org/10.1111/j.1467-7687.2009.00891.x

Mavilidi, M., Okely, A. D., Chandler, P., Cliff, D. P. \& Paas, F. (2015). Effects of integrated physical exercises and gestures on preschool children's foreign language vocabulary learning. Educational Psychology Review, 27(3), 413-426. https://doi.org/10.1007/s10648-015-9337-z

Mol, S., Bus, A., de Jong, M. (2009). Interactive book reading in early education: A tool to stimulate print knowledge as well as oral language. Review of Educational Research, 79, 979-1007. https://doi.org/10.3102/0034654309332561

Muñoz, C., \& Singleton, D. (2011). A critical review of age-related research on L2 ultimate attainment. Language Teaching, 44, 1-35. https://doi.org/10.1017/S0261444810000327

Oliver, R., \& Mackey, A. (2003). Interactional context and feedback in child ESL classrooms. Modern Language Journal, 87(4), 519-533. https://doi.org/10.1111/1540-4781.00205

Paas, F., \& Sweller, J. (2012). An evolutionary upgrade of cognitive load theory: using the human motor system and collaboration to support the learning of complex cognitive tasks. Educational Psychology Review, 24, 27-45. https://doi.org/10.1007/s10648-011-9179-2

Pearson, B.Z., Fernández, S. C., \& Oller, D. K. (1993). Lexical development in bilingual infants and toddlers: comparison to monolingual norms. Language Learning, 43(1), 93-120. https://doi.org/10.1111/j.1467-1770.1993.tboo174.x

Peck, S. (1978). Child-child discourse in second language acquisition. In E. M. Hatch (Ed.), Second language acquisition: A book of readings (pp. 383-40o). Rowley, MA: Newbury House.

Peña, E. D., Bedore, L. M., \& Zlatic-Giunta, R. (2002). Category-generation performance of bilingual children: the influence of cognition, category, and language. Journal of Speech, Language, and Hearing Research, 45, 938-947. https://doi.org/10.1044/1092-4388(2002/076)

Pérez, A. M., Peña, E. D., \& Bedore, L.M. (2010). Cognates facilitate word recognition in young Spanish-English bilinguals' test performance. Early Child Services (San Diego), 4(1), 55-67. 
Pesce, C., Crova, C., Cereatti, L., Casella, R., \& Bellucci, M. (2009). Physical activity and mental performance in preadolescents. Mental Health and Physical Activity, 2(1), 16-22. https://doi.org/10.1016/j.mhpa.2009.02.001

Pham, G. (2016). Pathways for learning two languages: Lexical and grammatical associations within and across languages in sequential bilingual children. Bilingualism: Language and Cognition, 19(5), 928-938. https://doi.org/10.1017/S1366728915000899

Porter, A. (2016). A helping hand with language learning French vocabulary with gesture. Language Learning Journal, 44(2), 236-256. https://doi.org/10.1080/09571736.2012.750681

Roberts, T. A. (2008). Home storybook reading in primary or second language with preschool children: Evidence of equal effectiveness for second-language vocabulary acquisition. Reading Research Quarterly, 43(2), 103-130. https://doi.org/10.1598/RRQ.43.2.1

Rohde, A., \& Tiefenthal, C. (2000). Fast mapping in early L2 lexical acquisition. Studia Linguistica, 54(2), 167-174. https://doi.org/10.1111/1467-9582.00057

Rowe, M.L., Silverman, R. D., \& Mullan, B.E. (2013). The role of pictures and gestures as nonverbal aids in preschoolers' word learning in a novel language. Contemporary Educational Psychology, 38(2), 109-117. https://doi.org/10.1016/j.cedpsych.2012.12.001

Schmidt, R. W. (1983). Interaction, acculturation, and the acquisition of communicative competence: A case study of an adult. In N. Wolfson \& E. Judd (Eds.), Sociolinguistics and language acquisition (pp. 137-174). Rowley, MA: Newbury House.

Schmidt, R. (1994). Deconstructing consciousness in search of useful definitions for applied linguistics. AILA Review, 11, 11-26.

Schmitt, N. (2014). Size and depth of vocabulary knowledge: What the research shows. Language Learning, 64(4), 913-951. https://doi.org/10.1111/lang.12077

Sebastian-Galles, N. (2010). Bilingual language acquisition: Where does the difference lie? Human Development, 53, 245-255. https://doi.org/10.1159/oo0321282

Shintani, N. (2011). A comparative study of the effects of input-based and production-based instruction on vocabulary acquisition by young EFL learners. Language Teaching Research, 15, 137-158. https://doi.org/10.1177/1362168810388692

Shintani, N. (2012). Input-based tasks and the acquisition of vocabulary and grammar: A process-production study. Language Teaching Research, 16(2), 253-279. https://doi.org/10.1177/1362168811431378

Shintani, N., \& Ellis, R. (2014). Tracking 'learning behaviours' in the incidental acquisition of two dimensional adjectives by Japanese beginner learners of L2 English. Language Teaching Research, 18(4), 521-542. https://doi.org/10.1177/1362168813519885

Silverman, R. (2007a). A comparison of three methods of vocabulary instruction during readalouds in kindergarten. The Elementary School Journal, 108(2), 97-113. https://doi.org/10.1086/525549

Silverman, R. (2007b). Vocabulary development of English-language and English-only learners in kindergarten. The Elementary School Journal, 107(4), 365-383. https://doi.org/10.1086/516669

Silverman, R., \& Hines, S. (2009). The effects of multimedia-enhanced instruction on the vocabulary of English-language learners and non-English-language learners in prekindergarten through second grade. Journal of Educational Psychology, 101(2), 305-314. https://doi.org/10.1037/aoo14217

Stahl, S. A., \& Fairbanks, M. M. (1986). The effects of vocabulary instruction: A model-based meta-analysis. Review of Educational Research, 56, 72-110.

https://doi.org/10.3102/00346543056001072 
Steele, S.C., \& Mills, M. T. (2011). Vocabulary intervention of school-age children with language impairment: A review of evidence and good practice. Child Language Teaching and Therapy, 27(3), 354-370. https://doi.org/10.1177/0265659011412247

Takanishi, R., \& Menestrel, S. L. (2017). Promoting educational success of children and youth learning English: Promising futures. Washington, DC: The National Academies Press. https://doi.org/10.17226/24677

Tellier, M. (2008). The effect of gestures on second language memorization by young children. Gesture, 8(2), 219-235. https://doi.org/10.1075/gest.8.2.06tel

Tomporowski, P.D., Davis, C. L., Miller, P.H., \& Naglieri, J. A. (2008). Exercise and children's intelligence, cognition, and academic achievement. Educational Psychology Review, 20, 111-131. https://doi.org/10.1007/s10648-007-9057-0

Tonzer, C., Lotto, L., \& Job, R. (2009). L2 vocabulary acquisition in children: Effects of learning method and cognate status. Language Learning, 59(3), 623-646.

https://doi.org/10.1111/j.1467-9922.2009.00519.x

Toumpaniari, K., Loyens, S., Marilidi, M., \& Paas, F. (2015). Preschool children's foreign language vocabulary learning by embodying words through physical activity and gesturing. Educational Psychology Review, 27, 445-456.

https://doi.org/10.1007/s10648-015-9316-4

Uccelli, P., \& Páez, M.M. (2007). Narrative and vocabulary development of bilingual children from kindergarten to first grade: developmental changes and associations among English and Spanish skills. Language, Speech, and Hearing Services in Schools, 38, 225-36. https://doi.org/10.1044/0161-1461(2007/024)

Uchikoshi, Y. (2006). English vocabulary development in bilingual kindergarteners: What are the best predictors? Bilingualism: Language and Cognition, 9, 33-49. https://doi.org/10.1017/S1366728905002361

Ulanoff, S., \& Pucci, S. (1999). Learning words form books: The effects of read aloud on second language vocabulary acquisition. Bilingual Research Journal, 23(4), 409-422. https://doi.org/10.1080/15235882.1999.10162743

Verhallen, M. J. A. J., \& Bus, A. G. (2010). Low-income immigrant pupils learning vocabulary through digital picture storybooks. Journal of Educational Psychology, 102(1), 54-61. https://doi.org/10.1037/aoo17133

Vermeer, A. (2001). Breadth and depth of vocabulary in relation to L1/L2 acquisition and frequency of input. Applied Linguistics, 22, 217-234.

Westermann, G., \& Mani, N. (2018). (Eds.). Early word learning. London: Routledge.

Wolters, B. (2006). Lexical network structures and L2 vocabulary acquisition: the role of L1 lexical/conceptual knowledge. Applied Linguistics, 27(4), 741-747. https://doi.org/10.1093/applin/amlo36

Wong-Fillmore, L. (1976). The second time around: Cognitive and social strategies in second language acquisition (Unpublished doctoral dissertation). Stanford University, Stanford, CA.

Wood, D. (2015). Fundamentals of formulaic language: An introduction. London: Bloomsbury. Yoshida, M. (1978). The acquisition of English vocabulary by a Japanese-speaking child. In E. M. Hatch (Ed.), Second language acquisition: A book of readings (pp. 91-100). Rowley, MA: Newbury House.

Yow, W. Q., Li, X., Lam, S., Gliga, T., Chong, Y. S., Kwek, K., \& Broekman, B. F. P. (2017). A bilingual advantage in 54-month-olds' use of referential cues in fast mapping. Developmental Science. https://doi.org/10.1111/desc.12482 


\section{Address for correspondence}

Yuko Goto Butler

University of Pennsylvania

3700 Walnut Street

Philadelphia PA, 19104-6216

USA

ybutler@upenn.edu

\section{Biographical note}

Yuko Goto Butler is Professor of Educational Linguistics at the Graduate School of Education at the University of Pennsylvania. She is also the director of Teaching English to Speakers of Other Languages (TESOL) program at Penn. Her research focuses on the improvement of second and foreign language education among young learners in the U.S. and Asia in response to the diverse needs of an increasingly globalizing world. 